\title{
Non-A, non-B aortic dissections: Unresolved issues
}

\author{
Bradley G. Leshnower, MD
}

\author{
From the Division of Cardiothoracic Surgery, Joseph B. Whitehead Department of Surgery, Emory School of \\ Medicine, Atlanta, Ga. \\ Disclosures: Author has nothing to disclose with regard to commercial support. \\ Received for publication Aug 5, 2018; accepted for publication Aug 10, 2018; available ahead of print Sept 20, \\ 2018. \\ Address for reprints: Bradley G. Leshnower, MD, Division of Cardiothoracic Surgery, Emory University School \\ of Medicine, 1365 Clifton Rd NE, Suite A2257, Atlanta, GA 30322 (E-mail: bleshno@emory.edu). \\ J Thorac Cardiovasc Surg 2019;157:74 \\ $0022-5223 / \$ 36.00$ \\ Copyright $\Subset 2018$ by The American Association for Thoracic Surgery \\ https://doi.org/10.1016/j.jtcvs.2018.08.016
}

One of the most challenging aspects in the management of acute aortic dissection (AAD) is the unpredictable behavior of the dissected aorta. In the current issue of the Journal, Trimarchi and colleagues ${ }^{1}$ address another unpredictable scenario in AAD, the "non-A, non-B" AAD in which the primary tear is located in the aortic arch. These authors analyzed 368 patients with primary arch tears from the International Registry of Acute Aortic Dissection (IRAD) database in an attempt to provide insight into the behavior of this rare, perplexing variation of AAD. ${ }^{1}$

The authors categorized these primary arch tears on the basis of antegrade or retrograde extension of the dissection flap, creating an "Arch A" group of 228 patients with ascending aortic involvement and an "Arch B" group of 140 patients without ascending aortic involvement. Of note, $30.7 \%$ of the patients in the Arch A group presented with shock, and $77.6 \%$ of patients underwent emergency open surgical repair with a resultant in-hospital mortality of $15.3 \%$. Endovascular or medical therapy had a mortality rate of approximately $25 \%$, and the most common cause of death was aortic rupture in $26 \%$ of patients. In contrast, $51 \%$ of patients in the Arch B group received medical management, $25 \%$ of patients underwent endovascular therapy, and only $19 \%$ of patients underwent open surgical repair. Mortality was $31 \%$ with open surgical repair, $14.3 \%$ in the endovascular group, and $13.9 \%$ in the medical cohort. The most common cause of mortality in the Arch B group was stroke, which occurred in $30 \%$ of patients.

Lessons learned from this analysis of the IRAD database are as follows. Patients with a primary arch tear involving the ascending aorta should be treated as having type A AAD and undergo emergency open surgical repair. There is a high risk of aortic rupture for those patients managed with alternative therapy. Patients presenting with malperfusion or rupture, and a primary arch tear with dissection extending into the descending/thoracoabdominal aorta without ascending aortic involvement should undergo

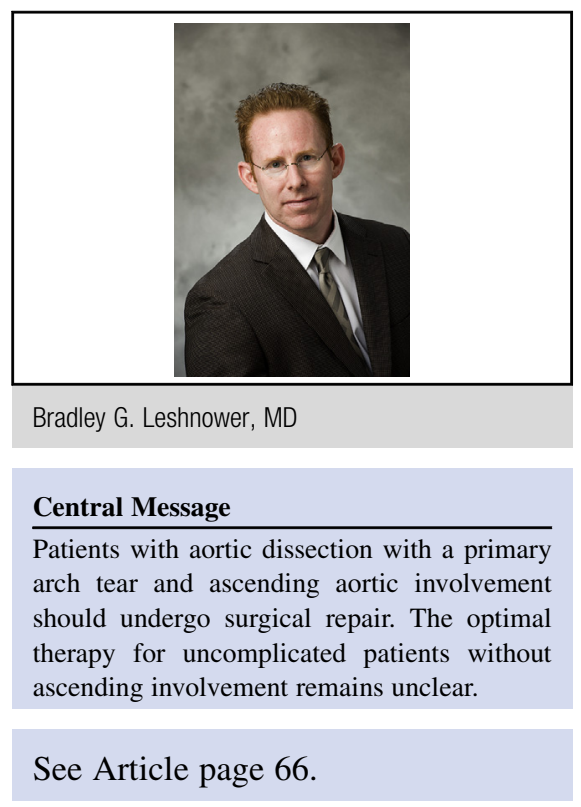

surgical or endovascular intervention. If the tear is located in Zone 2, thoracic endovascular aortic repair should be performed if technically feasible. If the tear is more proximal or Zone 2 is of inadequate length, then ascending/total arch replacement with frozen elephant trunk represents the optimal therapy. This strategy upholds a fundamental principle of AAD treatment: eradication (excision or exclusion) of the primary tear to eliminate antegrade false lumen perfusion.

However, the current analysis does not provide sufficient data to determine the optimal treatment of patients with an "uncomplicated" arch tear without ascending involvement, which represented $40 \%$ of the patients in the Arch B group. This is the group that needs further detailed analysis. Although one could treat these patients as having an uncomplicated Type B with medical therapy alone, progression of dissection occurred in $14 \%$ of patients, which likely contributed to the $30 \%$ incidence of lethal stroke. These data argue that uncomplicated Arch B does not behave like an uncomplicated type B, and perhaps a more aggressive approach is warranted. Further analysis from the IRAD database is required to determine the optimal management of these patients.

\section{Reference}

1. Trimarchi S, de Beaufort HWL, Tolenaar JL, Bavaria JE, Desai ND, Di Eusanio M, et al. Acute aortic dissections with entry tear in the arch: a report from the International Registry of Acute Aortic Dissection. J Thorac Cardiovasc Surg. 2019;157:66-73. 